\title{
La auditoría interna como herramienta de gestión para el control en los gobiernos autónomos descentralizados de la provincia de Morona Santiago
}

\author{
Internal Audit as a Management Tool for Control in the Decentralized Autonomous Governments in the \\ Morona Santiago Province
}

A auditoria interna como ferramenta de gestão para o controle nos governos autónomos descentralizados da província de Morona Santiago

Ana Alexandra López Jara

Universidad Católica de Cuenca, Ecuador

ORCID: http://orcid.org/0000-0001-6905-9025

DOI: https://doi.org/10.11144/Javeriana.cc19-47.aihg Redalyc: http://www.redalyc.org/articulo.oa?id=151556994004

Marlene Cañizares Roig

Universidad de La Habana, Cuba

ORCID: http://orcid.org/0000-0002-8433-167X

Fecha de recepción: 03 Marzo 2017

Fecha de aprobación: 21 Mayo 2018

\author{
Mónica Patricia Mayorga Diaz \\ Universidad Regional Autónoma de Los Andes, Cuba \\ monikmayorgad@gmail.com \\ ORCID: http://orcid.org/0000-0003-3071-236X
}

\section{Resumen:}

El control interno provee de una seguridad razonable a las operaciones administrativas y financieras de las instituciones; en la discusión sobre modelos de respuesta a los riesgos se presenta el modelo de control interno Committee of Sponsoring Organizations, (COSO), seleccionado por garantizar lo siguiente: 1) cumplimiento de leyes y regulaciones; 2) confiabilidad en la información financiera, y 3) salvaguarda de activos. Esta investigación se orientó hacia la necesidad de evaluar comparativamente el control interno de las unidades de auditoría interna pertenecientes a los gobiernos autónomos descentralizados cantonales de la provincia de Morona Santiago y a conocer su influencia sobre el control de gestión institucional. Para efectos del estudio se empleó una muestra de nueve de los trece cantones de la provincia seleccionada; la metodología para obtener información de la gestión de las unidades de auditoría interna sobre el control institucional, se fundamentó en entrevistas a los directores administrativos y financieros, y en la aplicación de un cuestionario de evaluación del control interno dirigido a los auditores internos o a los responsables de esta área en una entidad. La conclusión fundamental indica que el cumplimiento de las instituciones públicas con las normas técnicas de control interno dispuestas por la Contraloría General del Estado, bajo supervisión de las unidades de auditoría interna, promueve garantías razonables para la consecución eficiente de sus objetivos.

Palabras clave: sector público, auditoría pública, control interno.

\section{Abstract:}

Internal control provides the administrative and financial operations in the institutions with a reasonable safety. In the discussion on the risk response models there is an internal control model named Committee of Sponsoring Organizations (COSO), which was chosen as it guarantees: 1) compliance with the laws and regulations; 2) reliability in the financial information; and 3) assets safeguard. This research is driven by the need to comparatively assess the internal control in the internal audit units belonging to decentralized autonomous cantons of the Morona Santiago Province and to know its influence on the institutional management control. To the effects of this study, a sample with nine out of thirteen cantons in the said province was used. The methodology to obtain information on the management of the internal audit units regarding the institutional control was based in interviews to administrative and financial directors as well as the application of an internal control assessment questionnaire targeting either the internal auditors or other persons responsible for this area in the institutions. The fundamental conclusion states that, inside every public institution, the compliance with the internal control technical standards provided by the General Comptroller's Office of the State and supervised by the internal audit units promotes reasonable guarantees to attain efficiently their objectives.

Keywords: public sector, public audit, internal control. 


\section{Resumo:}

O controle interno fornece segurança razoável sobre as operações administrativas e financeiras das instituições; na discussão sobre modelos de resposta ao risco apresenta-se o modelo de controle interno Committee of Sponsoring Organizations (COSO), selecionado por garantir o seguinte: 1) cumprimento de leis e regulamentações; 2) confiabilidade na informação financeira, e 3) salvaguarda de ativos. Esta pesquisa foi orientada para a necessidade de avaliar comparativamente o controle interno das unidades de auditoria interna pertencentes aos governos autónomos descentralizados cantonais da província de Morona Santiago e a conhecer a influencia sobre o controle de gestão institucional. Para fins do estudo empregou-se amostra de nove dos treze cantões da província selecionada; a metodologia para obter informação da gestão das unidades de auditoria interna sobre o controle institucional, fundamentou-se em entrevistas aos diretores administrativos e financeiros e na aplicação de um inquérito de avaliação do controle interno direcionado aos auditores internos ou os responsáveis desta área em uma entidade. A conclusão fundamental indica que o cumprimento das instituições públicas com as normas técnicas de controle interno dispostas pela Contraloría General del Estado, sob supervisão das unidades de auditoria interna, promove garantias razoáveis para a consecução eficiente dos seus objetivos.

Palavras-chave: setor público, auditoria pública, controle interno.

\section{Introducción}

La auditoría, desde sus orígenes, ha sido considerada una actividad profesional orientada a la identificación de fraudes mediante el examen de los estados financieros en las organizaciones; ya en el desarrollo industrial, para la ejecución de la auditoría financiera se considera el incremento de los riesgos inherentes a las actividades empresariales, por lo que en 1941 se creó el Instituto de Auditores Internos (IIA) con la finalidad de capacitar técnicamente a los auditores internos, y de diseñar normas que garanticen la correcta práctica de la auditoría interna.

La auditoría interna se caracterizó por ser una actividad autónoma de revisión y examen a las actividades operativas de la empresa, con el compromiso de promover el cumplimiento de los objetivos y la responsabilidad en la organización por medio de la supervisión y la asesoría. Esta función ha derivado en la especialización de los siguientes ámbitos: las auditorías financiera, de gestión, de control interno y de cumplimiento, entre otras. Estas especialidades pueden realizarse con un enfoque de auditoría interna o externa, bajo criterios de control y supervisión de los recursos públicos (García, 2016).

El control interno del sector público ecuatoriano, en cumplimiento del Acuerdo N. 39 de la Contraloría General del Estado, se orienta por los componentes del marco conceptual del COSO, es decir, ambiente de control, evaluación de riesgos, actividades de control, información y comunicación y supervisión (Internal Control Integrated Framework, 1992).

Las unidades de análisis en esta investigación corresponden a los sistemas de control interno de nueve áreas de auditoría interna de los gobiernos autónomos descentralizados cantonales pertenecientes a la provincia de Morona Santiago. El objetivo consiste en valorar el cumplimiento de las normas técnicas de control interno mediante el marco conceptual del COSO en estos gobiernos, bajo un enfoque cuanti-cualitativo, con un alcance descriptivo-explicativo, en el que se aplicaron métodos como el histórico-lógico para realizar un estudio que permitiera conocer la esencia del problema relacionado con el control interno como competencia de las unidades de auditoría interna.

\section{Marco conceptual del control y la auditoría interna en la administración pública y su aplicación en Ecuador}

Inicialmente, el control interno no expresaba su finalidad y resultaba difuso establecer la relación entre los objetivos institucionales y el control como naturaleza; en consecuencia, en 1949, el Instituto Americano de Contadores Públicos presentó en el boletín Statement on Auditing Standards (SAS) N. 1 , la subdivisión del control interno en controles contables encaminados a la confiabilidad de la información financiera. Cabe resaltar que esta aproximación hacia el control interno presenta algunas debilidades como estas: 
1. No expresa efectivamente ningún concepto de control interno.

2. No asume a la organización como un sistema coordinado y en constante movilidad.

3. Se limita a la salvaguarda de los activos e ignora otros aspectos como los pasivos y el capital o patrimonio de la organización.

4. Presupone la búsqueda de exactitud de datos contables, por lo cual desconoce las estimaciones contables.

Por consiguiente, la eficacia del control interno institucional se construye con el establecimiento de manuales y procedimientos para la gestión administrativa y financiera en una organización, lo que dará respuestas para mitigar los riesgos y las debilidades de control interno detectadas. En 1992, por primera vez, una organización voluntaria del sector privado interesada en mejorar la eficiencia de la información financiera mediante la ética empresarial publica el informe COSO, como un marco conceptual de control interno de aplicabilidad universal, diseñado para el fortalecimiento del sistema empresarial, mediante el diagnóstico de los riesgos y la implementación de acciones de control.

En ese sentido, Beasley, Prawitt y Rittenberg (2002) señalan que el modelo integral de control interno COSO integra criterios conjuntos del Instituto Americano de Contadores Públicos Autorizados (Aicpa), la Asociación Americana de Contadores Públicos (AAA), el Instituto de Auditores Internos (IIA), la Organización Internacional de Ejecutivos de Finanzas (FEI) y el Instituto de Gerencia Contable (IMA), para promover la confiabilidad en las operaciones.

De conformidad con el modelo conceptual COSO, el sistema de control interno está integrado por los siguientes componentes: ambiente de control, evaluación de riesgos, actividades de control, información y comunicación y supervisión, los mismos que se describen a continuación:

Ambiente de control: constituye el fundamento de la pirámide de control interno, tributando disciplina a la estructura que servirá de base para los demás componentes. De acuerdo con las Normas Técnicas de Control Interno (NTCI), se refiere al establecimiento de un entorno que estimule e influencie las tareas del personal con respecto al control de sus actividades (Contraloría General del Estado, 2009). Su importancia radica en la filosofía de la administración para consolidar bases que promuevan una eficiente funcionalidad del control interno, partiendo de un comportamiento ético de los miembros de la organización.

Valoración de riesgos: en este componente subyacen procesos de identificación, análisis y mitigación de los riesgos de la organización, como factores que promueven la consecución de los objetivos institucionales.

El riesgo es la probabilidad de ocurrencia de un evento no deseado que podría perjudicar o afectar adversamente a la entidad o su entorno. La máxima autoridad, el nivel directivo y todo el personal serán responsables de efectuar el proceso de administración de riesgos que implica metodología, estrategias, técnicas y procedimientos a través de los cuales las unidades administrativas identificarán, analizarán y tratarán los potenciales eventos que pudieran perjudicar la ejecución de sus procesos y el logro de sus objetivos (Contraloría General del Estado, 2009).

Actividades de control: en este componente se derivan los procedimientos y acciones de la entidad para reducir los impactos negativos en el desarrollo de las operaciones como consecuencia de la identificación de los riesgos. Las actividades de control se dan en toda la organización, en todos los niveles y en todas las funciones. Incluyen una diversidad de acciones de control de detección y prevención, como: separación de funciones incompatibles, procedimientos de aprobación y autorización, verificaciones, controles sobre el acceso a recursos y archivos, revisión del desempeño de operaciones, segregación de responsabilidad de autorización, ejecución, registro y comprobación de transacciones, revisión de procesos y acciones correctivas cuando se detectan desviaciones e incumplimientos (Contraloría General del Estado, 2009).

Información y comunicación: dentro del proceso de control, la comunicación debe ser oportuna y permanente; es necesario suministrar información relevante que facilite a cada miembro de la organización cumplir con las responsabilidades. Este componente está constituido por los métodos para registrar, procesar, resumir e informar sobre las operaciones técnicas, administrativas y financieras de una entidad. La calidad 
de la información que brinda el sistema le permite a la máxima autoridad adoptar decisiones adecuadas que permitan controlar las actividades de la entidad y preparar información confiable (Contraloría General del Estado, 2009).

Supervisión: con el afán de comprobar la funcionalidad de las actividades de control implementadas y que estas sean desarrolladas satisfactoriamente, es necesario realizar evaluaciones periódicas que permitan incluir acciones correctivas, si es necesario. La supervisión es el proceso que evalúa la calidad del funcionamiento del control interno en el tiempo y permite reaccionar en forma dinámica, cambiando cuando las circunstancias así lo requieran. Busca identificar controles débiles o insuficientes para promover su reforzamiento, así como asegurar que las medidas que son producto de los hallazgos de auditoría y los resultados de otras revisiones se atiendan de manera efectiva y con prontitud (Contraloría General del Estado, 2009).

A partir de la bibliografía consultada, en el primer componente del modelo de control interno COSO, ambiente de control, se definen los elementos teóricos fijados en manuales, códigos y demás documentos rectores de la ejecución de las operaciones; en el siguiente componente, evaluación de riesgos, se definen las estrategias para mitigar los riesgos identificados durante el giro operacional; en el componente de actividades de control se especifican las acciones que deben realizarse en cumplimiento de las responsabilidades de cada área, departamento o sección de la empresa. Los componentes de información y comunicación, y supervisión se consideran elementos permanentes que deben ejecutarse de forma simultánea en todos los componentes del modelo de control interno COSO mencionados en este apartado.

Para la auditoría interna, el estudio del control interno en una organización representa elementos de soporte para la gestión de sus funciones. De la revisión bibliográfica realizada a los autores Martínez (2006), Ablan y Méndez (2009), Gaitán y Niebel (2015), Acosta, Echeverría y Lozada (2017), Carrión, Mendoza-Vinces y Álava (2017), y Pacheco (2017), se conoce que las funciones de las unidades de auditoría interna surgen en 1930 como resultado de la evolución tecnológica de las actividades empresariales y de la adopción de los nuevos procesos de producción. En esa época, el auditor interno era reconocido por su actividad de análisis de la información financiera, lo que daba garantía de confiabilidad a los balances y a la supervisión del control interno. La función del auditor interno consistía, por una parte, en detectar errores contables; esto se debía, a que la contabilidad, al ser manual, ocasionaba una gran cantidad de errores y, por otra, en localizar por medio del análisis de libros, registros y planillas, eventuales fraudes y pérdidas del patrimonio del ente (Scrib, 2016).

Como efectos de la crisis de 1929, emergen fundamentos legales destinados a proteger la información financiera, principalmente en países desarrollados. En consecuencia, se exige a la administración, la veracidad en la información, y se deriva el interés de apoyarse en auditores externos para la fiscalización de los registros contables, para demostrar la exactitud y la confiabilidad financiera, además de la seguridad que soportaba el auditor interno.

Debido al rol que desempeñaba el auditor interno en relación con la información financiera, en 1941 se creó The Institute of Internal Auditor con el afán de impulsar la profesión dentro del sector empresarial. Considerando estos hechos, la auditoría interna toma fuerza y se reconoce como una profesión independiente de la administración, cuyo interés es garantizar confiabilidad en la información financiera y dar asesoría para el cumplimiento de los objetivos empresariales bajo los marcos de eficiencia y eficacia. En el criterio de Pickett (2007), la auditoría interna constituye una profesión imparcial y objetiva destinada a garantizar la eficiencia en las operaciones empresariales, mediante la fiscalización de la información financiera y la asesoría en las actividades; a través de su prisma sistemático, identifica los riesgos y mejora la gestión empresarial.

Para el sector público, la CGE define a la auditoría interna como una actividad independiente y objetiva de aseguramiento y asesoría, concebida para agregar valor y mejorar las operaciones de una organización; también evalúa el sistema de control interno, los procesos administrativos, técnicos, ambientales, financieros, legales, operativos, estratégicos y gestión de riesgos (Contraloría General del Estado, 2009). Mientras que en el sector privado, las competencias de la auditoría interna se definen mediante un estatuto aprobado por el Consejo de la Administración (Instituto de Auditoría Interna, 2002). 
El ejercicio de la auditoría interna en el sector público es competencia de las siguientes entidades: 1) la Contraloría General del Estado, mediante auditorías externas efectuadas por el personal; 2) la unidad de auditoría interna responsable en cada entidad, y 3 ) las personas naturales o jurídicas dedicadas a los servicios de auditoría. Las fases de la auditoría se inician con la programación de las actividades para el examen, posteriormente sigue la ejecución operativa, con el desarrollo de papeles de trabajo que soporten evidencia suficiente, competente y pertinente que serán presentados en el informe; concluido el proceso de auditoría se realiza la supervisión al cumplimiento de las recomendaciones.

Se reconoce que toda entidad que administre recursos estatales se encuentra bajo la supervisión del organismo máximo de control, la CGE, que junto con otras entidades gubernamentales conforman la sexta función del sector estatal denominado Control y transparencia social; enseguida se enuncia la organización del sector público ecuatoriano, de acuerdo con lo prescrito en la Constitución de la República:

1. Los organismos y dependencias de las funciones ejecutiva, legislativa, judicial, electoral y de transparencia y control social.

2. Las entidades que integran el régimen autónomo descentralizado.

3. Los organismos y entidades creados por la Constitución o la ley para el ejercicio de la potestad estatal, para la prestación de servicios públicos o para desarrollar actividades económicas asumidas por el Estado.Los organismos y entidades creados por la Constitución o la ley para el ejercicio de la potestad estatal, para la prestación de servicios públicos o para desarrollar actividades económicas asumidas por el Estado.

4. Las personas jurídicas creadas por acto normativo de los gobiernos autónomos descentralizados para la prestación de servicios públicos (Asamblea Nacional Constituyente, 2008).

Bajo la rectoría de la CGE se encuentra la dirección del Sistema de Control, Fiscalización y Auditoría del Estado, así como también la función de examinar, verificar y evaluar el cumplimiento de la visión, la misión y los objetivos de las instituciones del Estado de conformidad con la utilización de recursos y bienes públicos (Contraloría General del Estado, 2015). En garantía al control público institucional, la CGE, mediante el Artículo 14 de la Ley Orgánica de la Contraloría, dispone:

Las instituciones del Estado contarán con una unidad de auditoría interna que dependerá técnica y administrativamente de la CGE; para su creación o supresión emitirá informe previo. El personal auditor será nombrado, removido o trasladado por el Contralor General del Estado, y las remuneraciones y gastos para el funcionamiento de las unidades de auditoría interna serán cubiertos por las propias instituciones del Estado a las que ellas sirven y controlan (Ley Orgánica de la Contraloría General del Estado, 2015).

En virtud de lo expuesto, la auditoría interna es una actividad profesional de evaluación independiente dentro de una organización, cuya finalidad es examinar las operaciones contables, financieras y administrativas para la presentación de un servicio efectivo a los más altos niveles de dirección.

Los gobiernos autónomos descentralizados cantonales integran, dentro de la estructura organizacional, a las unidades de auditoría interna dispuestas por la Contraloría General del Estado. Entre las funciones principales de la auditoría interna, el Artículo 77 de la Ley Orgánica de la Contraloría General del Estado establece:

1) programar, organizar, dirigir, coordinar y controlar las actividades de la unidad a su cargo; 2) supervisar la calidad de los exámenes efectuados; 3 ) actuar con profesionalismo y verificar que el personal a su cargo proceda de la misma manera; 4) cumplir y hacer cumplir las disposiciones legales, reglamentarias, políticas, normas técnicas y demás regulaciones de la auditoría gubernamental, y 5) cumplir las demás obligaciones señaladas en la ley (Ley Orgánica de la Contraloría General del Estado, 2015).

Sin embargo, la vigilancia del Sistema de control interno se ha convertido en una responsabilidad compartida entre los servidores públicos y la unidad de auditoría interna; por ello, la Norma técnica de control interno $\mathrm{N}^{\circ} 100-03$ señala que: 
Las servidoras y servidores de la entidad son responsables de realizar las acciones y atender los requerimientos para el diseño, implantación, operación y fortalecimiento de los componentes del control interno de manera oportuna, sustentados en la normativa legal y técnica vigente, y con el apoyo de la auditoría interna como ente asesor y de consulta. (Contraloría General del Estado, 2009, pág. 4)

$\mathrm{Al}$ ser las unidades de auditoría interna integradas a los gobiernos autónomos descentralizados cantonales, los exámenes de auditoría se realizan de conformidad con las leyes, regulaciones y normativas emitidas por la Contraloría General del Estado; sin embargo, las instituciones públicas han creado manuales que incluyen políticas específicas para la unidad de auditoría interna. En el manual para la auditoría interna de la Empresa Metropolitana se argumenta que "las políticas para la auditoría interna son líneas de acción que proporcionan orientaciones de carácter general para ejecutar la auditoría en forma eficiente, efectiva, económica, ecológica, ética y equitativa" (Potable, 2004). Para el ejercicio de la auditoría interna se observarán, además, en forma obligatoria, las políticas de calidad establecidas por la norma ISO 9001.

1. La auditoría interna realizará auditorías de gestión y exámenes especiales de conformidad con lo establecido en el Artículo 14 de la Ley Orgánica de la Contraloría General del Estado.

2. Los auditores de esta unidad mantendrán independencia respecto a la operación o actividad auditada y no intervendrán en la autorización y aprobación de los procesos financieros, administrativos, operativos y ambientales del área administrativa auditada.

3. Los informes resultantes de las auditorías o exámenes especiales suscritos por el jefe de la unidad serán enviados a la Contraloría General del Estado para su aprobación y posteriormente tramitados a las autoridades y los funcionarios relacionados con el examen (Potable, 2004).

Las unidades de auditoría interna deben mantener comunicación con la CGE, en virtud de que los exámenes deben ser coordinados con la instancia de control superior y en cumplimiento de la normativa vigente. Los procedimientos y prácticas que se van a efectuar se harán en orden y con aprobación de la CGE, para lo cual deberán presentar un Plan Anual de Trabajo. La asesoría y asistencia técnica de la unidad de auditoría se caracteriza por ser una función de primer orden.

\section{Metodología}

La investigación desarrollada se caracteriza por ser de naturaleza descriptiva-explicativa, bajo un enfoque cuantitativo y cualitativo, para la evaluación del control interno de las unidades de auditoría interna en los gobiernos autónomos descentralizados cantonales de la provincia de Morona Santiago.

La experiencia se fundamentó en una elección intencional de nueve de las trece unidades de auditoría interna correspondientes a cada uno de los cantones de la provincia de Morona Santiago (Ecuador); es decir, se consideró el 69 \% del total de los gobiernos autónomos cantonales. La selección de los nueve cantones responde a aquellos que presentan una población mayor a 5000 habitantes; esta característica es también considerada al momento de la distribución de las transferencias corrientes del gobierno central. Los cantones sujetos de estudio fueron: Palora, Huamboya, Pablo Sexto, Taisha, Sucúa, Santiago de Méndez, Tiwintza, Limón Indanza y Gualaquiza.

Se aplicaron, por una parte, instrumentos cualitativos mediante entrevistas a los jefes administrativos y financieros de las instituciones y, por otra, instrumentos de investigación cuantitativos por medio del cuestionario de control interno que fue dirigido a los auditores internos de las instituciones investigadas o a delegados de control interno.

El método empleado para la evaluación del control interno fue el cuestionario, que incluyó 27 preguntas distribuidas en los cinco componentes del modelo de control interno COSO (Anexo 1); las preguntas se orientaron a verificar el cumplimiento de las normas de control interno emitidas por la Contraloría General 
del Estado. Para efectos de la valoración numérica se identificó el grado de funcionamiento del control básico y se ponderó cuantitativamente, de acuerdo con la importancia del control respecto a cada uno de los componentes, asignándole una equivalencia numérica de uno en la casilla destinada a "ponderación". Para la calificación se consideró como base la ponderación asignada a las preguntas y se calificó el funcionamiento de los controles, considerando las respuestas. Para concluir la evaluación del control interno se totalizaron las columnas de ponderación y calificación, y se obtuvieron dos cantidades, que transformadas en términos porcentuales permitieron conocer la confiabilidad del control interno y establecer el nivel de riesgo. El grado de confianza de la evaluación se interpreta como la solidez que deposita el investigador en los controles internos de la entidad, determinándose de esta manera el nivel de riesgo que presentan las áreas evaluadas. Para mayor interpretación se ha considerado la metodología de valoración del nivel de confianza y riesgo de la Contraloría General de Estado:

TABLA 1

Equivalencia de niveles de confianza y de riesgo

\begin{tabular}{|c|l|l|}
\hline $\begin{array}{c}\text { Calificación } \\
\text { porcentual }\end{array}$ & $\begin{array}{c}\text { Grado de } \\
\text { confianza }\end{array}$ & $\begin{array}{c}\text { Nivel de } \\
\text { riesgo }\end{array}$ \\
\hline $15-50 \%$ & 1. Bajo & 3. Alto \\
\hline $51-75 \%$ & 2. Medio & 2. Medio \\
\hline $76-95 \%$ & 3. Alto & 1. Bajo \\
\hline
\end{tabular}

Fuente: elaboración propia.

Se consideró como un elemento de análisis el nivel de confianza de la funcionalidad de los controles integrantes del sistema de control interno supervisado por las unidades de auditoría interna de los gobiernos autónomos descentralizados cantonales. Por otra parte, se analizó el nivel de riesgo de las operaciones, calificado como la inobservancia o la carencia de las disposiciones de control en el área, proceso o entidad sujeta a evaluación.

\section{Resultados y discusión}

De la investigación realizada sobre el control interno como gestión institucional de las unidades de auditoría interna de los gobiernos autónomos descentralizados cantonales, se presentan a continuación los principales resultados (Figura 1):

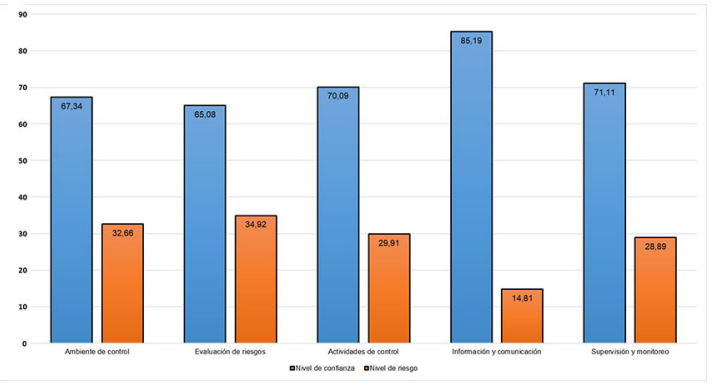

FIGURA 1.

Resultados de las diferentes variables del Modelo COSO I en las unidades de auditoría interna de los gobiernos autónomos descentralizados cantonales de la provincia de Morona Santiago.

Fuente: elaboración propia. 
El control interno difiere mucho entre las organizaciones, según factores como la naturaleza de sus operaciones, el tamaño y los objetivos que persiguen. Por ello, la presente investigación se centra en la evaluación de los cinco componentes del Modelo COSO I, como son: ambiente de control, evaluación de riesgos, actividades de control, información y comunicación, y supervisión y monitoreo en nueve unidades de auditoría interna de los gobiernos autónomos descentralizados de la provincia de Morona Santiago.

Considerando que todos los individuos que conforman una organización desarrollan el sistema de control interno, en sujeción a la normativa legal vigente y a los recursos asignados, se evidencian los resultados alcanzados por cada componente en las unidades de auditoría interna evaluadas. Al ser la unidad de auditoría interna considerada en el sector público un nivel de asesoría, el componente información y comunicación representa el nivel de confianza más elevado, seguido de los componentes de supervisión, actividades de control y evaluación de riesgos, respectivamente. Este último componente responde a las actividades planificadas y ejecutadas por las entidades como respuesta a los riesgos que afecten la consecución de los objetivos institucionales. A continuación, se exponen de manera comparativa, en la Figura 1, los niveles de confianza y riesgo de cada componente de control interno evaluado en los cantones seleccionados:

TABLA 2

Resultados de la evaluación del cumplimiento de control interno por cantón en la provincia de Morona Santiago

\begin{tabular}{|l|c|c|c|c|c|c|c|c|c|c|}
\hline & \multicolumn{2}{|c|}{$\begin{array}{c}\text { Ambiente de } \\
\text { control }\end{array}$} & \multicolumn{2}{c|}{$\begin{array}{c}\text { Evaluación de } \\
\text { riesgos }\end{array}$} & \multicolumn{2}{c|}{$\begin{array}{c}\text { Actividades de } \\
\text { control }\end{array}$} & \multicolumn{2}{|c|}{$\begin{array}{l}\text { Información y } \\
\text { comunicación }\end{array}$} & \multicolumn{2}{c|}{ Seguimiento } \\
\cline { 2 - 12 } & $\begin{array}{c}\text { Nivel de } \\
\text { confianza } \\
\%\end{array}$ & $\begin{array}{c}\text { Nivel de } \\
\text { riesgo } \\
\%\end{array}$ & $\begin{array}{c}\text { Nivel de } \\
\text { confianza } \\
\%\end{array}$ & $\begin{array}{c}\text { Nivel de } \\
\text { riesgo } \%\end{array}$ & $\begin{array}{c}\text { Nivel de } \\
\text { confianza } \\
\%\end{array}$ & $\begin{array}{c}\text { Nivel de } \\
\text { riesgo } \\
\%\end{array}$ & $\begin{array}{c}\text { Nivel de } \\
\text { confianza } \\
\%\end{array}$ & $\begin{array}{c}\text { Nivel de } \\
\text { riesgo } \\
\%\end{array}$ & $\begin{array}{c}\text { Nivel de } \\
\text { confianza } \\
\%\end{array}$ & $\begin{array}{c}\text { Nivel de } \\
\text { riesgo \% }\end{array}$ \\
\hline $\begin{array}{l}\text { Limón } \\
\text { Indanza }\end{array}$ & 72,73 & 27,27 & 14,29 & 85,71 & 76,92 & 23,08 & 83,33 & 16,67 & 100 & 0 \\
\hline Sucúa & 39,39 & 60,61 & 71,43 & 28,57 & 38,46 & 61,54 & 100 & 0 & 40 & 60 \\
\hline Gualaquiza & 81,82 & 18,18 & 28,57 & 71,43 & 76,92 & 23,08 & 83,33 & 16,67 & 80 & 20 \\
\hline Palora & 90,91 & 9,09 & 100 & 0 & 92,31 & 7,69 & 100 & 0 & 80 & 20 \\
\hline Huamboya & 90,91 & 9,09 & 100 & 0 & 92,31 & 7,69 & 100 & 0 & 100 & 0 \\
\hline $\begin{array}{l}\text { Pablo } \\
\text { Sexto }\end{array}$ & 96,97 & 3,03 & 100 & 0 & 100 & 0 & 100 & 0 & 100 & 0 \\
\hline Taisha & 87,88 & 12,12 & 100 & 0 & 84,62 & 15,38 & 100 & 0 & 100 & 0 \\
\hline $\begin{array}{l}\text { Santiago } \\
\text { de Méndez }\end{array}$ & 45,45 & 54,55 & 71,43 & 28,57 & 69,23 & 30,77 & 100 & 0 & 40 & 60 \\
\hline Tiwintza & 27,26 & 72,73 & 71,43 & 28,57 & 46,15 & 53,85 & 5 & 95 & 40 & 60 \\
\hline
\end{tabular}

Fuente: elaboración propia.

Cuando se evalúa la primera unidad de auditoría interna correspondiente al gobierno autónomo descentralizado del cantón de Limón Indanza (Figura 1), el componente de seguimiento presenta un nivel de confianza del $100 \%$, como resultado de la gestión de la unidad de auditoría interna sobre la evaluación de los controles implementados, de manera específica en los procesos de contratación pública. Por otro lado, el componente de evaluación de riesgos representa un nivel de confianza del 14,29\%, considerado como bajo, debido a las limitadas herramientas de gestión empleadas para identificar riesgos internos o externos y a la escasa participación de los miembros de la institución en programas para mitigar y administrar eventos que afecten negativamente la misión institucional.

Se destacan niveles de confianza elevados en los componentes de ambiente de control, actividades de control e información y comunicación, en un rango estándar del 72,73\%,76,92 \% y 83,33 \%, respectivamente; esto se debe a las disposiciones escritas para el ejercicio de las actividades operativas, partiendo del código de ética institucional y del manual de procesos. 
En la evaluación de la unidad de auditoría interna del gobierno autónomo descentralizado del cantón de Sucúa (Figura 1), el componente de información y comunicación presenta un nivel de confianza del 100 \%, en razón a la evidencia documental con que la entidad respalda la gestión de la comunicación interna en procesos administrativos, financieros y operativos. Sin embargo, los componentes de ambiente de control, actividades de control y seguimiento mantienen un rango que oscila entre 39,39\%, 38,46\% y $40 \%$ del nivel de confianza, respectivamente. Estos niveles de eficacia caracterizan a entidades en las que las operaciones administrativas y financieras de los servidores públicos no se orientan con reglamentos o disposiciones internas diseñadas para las necesidades de las instituciones, sino que únicamente se tienen en cuenta los reglamentos generales para el sector público. El nivel de confianza del componente de evaluación de los riesgos es del 71,43 \% y evidencia que se priorizan los riesgos mediante matrices de áreas o departamentos, en función de la importancia relativa y la frecuencia con la que se presentan.

En el cantón de Gualaquiza, de acuerdo con los resultados de la evaluación del control interno (Figura 1), se registra cierta similitud entre el nivel de confianza de los componentes de ambiente de control, seguimiento e información y comunicación, del $81,82 \%, 83,33 \%$ y $80 \%$, comparativamente; esto tiene que ver con que la entidad cumple con las bases legales pertinentes, de acuerdo con las competencias y funciones establecidas en el Código Orgánico de Organización Territorial, Autonomía y Descentralización. Sin embargo, se destaca una diferencia porcentual en los componentes de actividades de control del 76,92\% y evaluación de riesgos del $74,43 \%$, porque la entidad sujeta a estudio no ha estructurado formalmente mecanismos para la identificación y administración de riesgos que afecten las operaciones.

Los componentes de evaluación de los riesgos e información y comunicación, en el cantón de Palora, presentan un nivel de confianza del $100 \%$, es decir que los recursos y esfuerzos de la entidad tienden al cumplimiento de sus objetivos (Figura 1). La comunicación entre los miembros se realiza por medio de canales óptimos y oportunos, notificando las responsabilidades individuales en el control y desarrollo de las operaciones asignadas. En relación con los componentes de ambiente de control, actividades de control y seguimiento, los niveles de confianza alcanzan el $90,91 \%$, el $92,31 \%$ y el $80 \%$, respectivamente, lo que significa que son entornos de trabajo adecuados, con un ambiente de disciplina y una estructura que contribuye al cumplimiento de las políticas y procedimientos institucionales. El monitoreo a las operaciones es constante, sugiriendo y adaptando las modificaciones necesarias para mejorar la funcionalidad del sistema de control interno institucional.

En los resultados de la evaluación del control interno en el cantón de Huamboya se encuentra un nivel de confianza del $100 \%$ en tres componentes: evaluación de los riesgos, seguimiento e información y comunicación (Figura 1), debido a que la entidad ha diseñado procesos funcionales en observancia de la misión y la visión institucionales, identificando y mitigando riesgos mediante planes de acción. Además, se destacan sistemas de información eficientes, orientados a entregar informes respecto a los resultados de la gestión. Para garantizar que los procesos implementados alcancen los objetivos planificados, se ha adoptado un sistema de supervisión en cada área de la institución. En los componentes de ambiente de control y actividades de control se evidencia un porcentaje similar en los niveles de confianza del 90,91\% y el 92,31 $\%$, respectivamente; en consecuencia, las operaciones administrativas, financieras y operativas se cumplen en orden, de acuerdo con los manuales, las bases legales y las normativas pertinentes.

El gobierno autónomo descentralizado del cantón de Pablo Sexto (Figura 1) presenta un nivel de confianza del $100 \%$ en los componentes de evaluación de riesgos, actividades de control, seguimiento e información y comunicación, seguidos por el componente de ambiente de control, con un nivel de confianza del 96,97 \%. La estructura organizativa se encuentra correctamente definida en cumplimiento de las disposiciones, políticas y regulaciones establecidas; la filosofía de control interno que mantiene la alta dirección y los servidores sobre la inclusión de acciones de mejora es relevante. Los sistemas de información y comunicación interna y externa permiten el registro y procesamiento oportuno de la gestión institucional. 
El escenario de control interno en el cantón de Taisha (Figura 1) expone un nivel de confianza alta en los componentes de evaluación de los riesgos, información y comunicación y seguimiento, seguidos de los componentes de ambiente de control y actividades de control, con niveles de confianza del 87,88 \% y el 84,62 $\%$, correspondientemente. El compromiso de los funcionarios y directivos que conforman la entidad permite que la ocurrencia de eventos que afecten la consecución de los objetivos sea identificada, analizada y mitigada oportunamente a través de procesos de monitoreo permanentes.

La unidad de auditoría interna del gobierno autónomo descentralizado del cantón de Santiago de Méndez (Figura 1) presenta un alto nivel de confianza en el componente información y comunicación, con un rendimiento del $100 \%$, a diferencia de los componentes de evaluación de riesgos y actividades de control, ambiente de control y seguimiento, con niveles de confianza en rangos de 71,43\%, 69,23\%, 45,45\% y 40 $\%$, respectivamente. Para que las actividades de control de una entidad se relacionen directamente con los objetivos, deben enmarcarse en un plan a lo largo de un periodo, precedido de un análisis de costo/beneficio que permita determinar su contribución y conveniencia con el cumplimiento de objetivos; en consecuencia, la adopción de medidas oportunas que permitan corregir las deficiencias de control promueven la eficiencia y la eficacia en las operaciones de la institución.

Finalmente, en la unidad de auditoría interna del gobierno autónomo descentralizado del cantón de Tiwintza (Figura 1) se evidencia una débil estructura organizativa, limitados recursos de planificación institucional y una escasa comunicación interna y externa. Los controles internos implementados generan riesgos, caracterizando un nivel de confianza del 71,43\% en el componente evaluación de riesgos; por otro lado, los componentes de actividades de control y seguimiento con niveles de confianza del $46,15 \%$ y el 40 $\%$, respectivamente, debido al cumplimiento, en menor medida, de actividades de aprobación, autorización, verificación, inspección y revisión de indicadores de gestión para la salvaguarda de activos. En el componente de ambiente de control se expone un rango del 27,27 \% de confianza, y en el componente de información y comunicación hay un resultado bajo de confianza, lo que de acuerdo con la metodología empleada es considerado un débil nivel de asesoría y control de la unidad de auditoría interna.

\section{Conclusiones}

1. Mediante el Acuerdo 039, la Contraloría General del Estado presenta las normas de control interno dirigidas a todas las entidades, organismos del sector público y personas jurídicas de derecho privado que dispongan de recursos públicos; estas han sido diseñadas bajo el marco conceptual del Informe COSO, en el que se definen los siguientes componentes integradores: ambiente de control, evaluación de riesgos, actividades de control, información y comunicación, y supervisión.

2. El objetivo de las normas de control interno del sector público es regular y garantizar las acciones de titulares, servidoras y servidores de cada entidad u organismo, según su competencia y en función de la naturaleza jurídica de la entidad, para que desarrollen, expidan y apliquen los controles internos que provean una seguridad razonable en salvaguarda de su patrimonio.

3. Las unidades de auditoría interna, en cumplimiento de sus funciones y con sujeción al marco conceptual COSO I, son herramientas de gestión encargadas de lo siguiente:

- Vigilar el cumplimiento del componente de ambiente de control, respecto a la estructura orgánica y funcional, a la creación de bases legales para los procesos y a la organización de las actividades a través de la planificación.

- En la evaluación de riesgos, la unidad de auditoría interna promueve estrategias y planes de acción para identificar, mitigar y administrar los riesgos que afecten el cumplimiento de la misión institucional. 
- Las actividades de control incluyen acciones de revisión, autorización y supervisión de las operaciones desarrolladas.

- La información y comunicación se evidencia en el rol de la unidad de auditoría interna, por los informes y documentos que surgen como resultado de los exámenes de auditoría que realizan de forma permanente.

- La supervisión a las operaciones es permanente, incluyendo acciones de control a los indicadores de gestión institucional y exámenes de auditoría interna, así como la asesoría en temas administrativos, operativos y financieros, de acuerdo con las bases legales emitidas por la Contraloría General del Estado.

4. Las unidades de análisis de esta investigación a las que se les aplicó la lógica de intervención, fueron las áreas de auditoría interna de los gobiernos autónomos descentralizados cantonales de Palora, Huamboya, Pablo Sexto, Taisha, Sucúa, Santiago de Méndez, Tiwintza, Limón Indanza y Gualaquiza, en donde se destacan niveles de confianza elevados en los componentes de ambiente de control, actividades de control e información y comunicación, con resultados mayores al 70 $\%$, lo que significa que los miembros que conforman la institución exhiben un comportamiento ético, además de que aplican una adecuada segregación y cumplimiento de funciones con base en un sistema de monitoreo. Se reconoce, además, que como característica de las unidades de auditoría interna se han logrado diseñar procesos funcionales en cumplimiento de la misión y la visión institucionales, identificando y mitigando riesgos a través de planes de acción. Finalmente, se conoce la existencia de sistemas de información eficientes orientados a entregar informes respecto a los resultados de gestión, con elementos de supervisión en cada área de la institución.

5. Como resultado importante, el componente de ambiente de control presenta un mayor nivel de confianza en el gobierno autónomo descentralizado del cantón de Pablo Sexto, seguido de los cantones de Palora y Huamboya, con porcentajes similares, demostrando el conocimiento de las bases legales pertinentes para la auditoría del sector público, emitidas por el órgano rector, la Contraloría General del Estado. Los cantones de Tiwintza, Sucúa y Santiago de Méndez registran un nivel de riesgo alto en este componente, a pesar de que se realizan exámenes de auditoría y presentan un limitado archivo permanente sobre las bases legales y documentos de control interno.

6. El escenario de la evaluación de riesgo adoptado por las unidades de auditoría interna de los cantones de Palora, Huamboya, Pablo Sexto y Taisha es asertivo, con un nivel de confianza superior al $95 \%$, debido al diseño y a la aplicación de estrategias dentro de las operaciones. Por otra parte, el componente de actividades de control presenta un nivel de confianza superior al $75 \%$ en casi la totalidad de los cantones, excepto en el gobierno autónomo descentralizado del cantón de Sucúa, debido al alto cumplimiento de las Normas técnicas de control interno emitidas por la Contraloría General del Estado en cada área, departamento y operación en el servicio público.

7. Al representar las unidades de auditoría interna un nivel de asesoría, el componente de información y comunicación, del modelo de control interno COSO, presenta niveles de confianza altos, superiores al $80 \%$ en la totalidad de la muestra analizada. Con similar comportamiento se caracteriza el componente de seguimiento, excepto en los cantones de Sucúa, Santiago de Méndez y Tiwintza, que presentan un nivel de riesgo superior al $50 \%$, lo que podría afectar la salvaguarda de las operaciones y la adopción de medidas correctivas para la evaluación de la funcionalidad del control interno.

\section{Referencias bibliográficas}

Ablan, N., \& Méndez, Z. (2009). Los sistemas de control interno en los entes descentralizados estatales y municipales desde la perspectiva COSO. Visión gerencial, 7. 
Acosta, C., Echeverría, B., \& Lozada, M. (2017). Auditoría integral aplicada al sector público.

Asamblea Nacional Constituyente. (2008). Constitución Política de la República del Ecuador. Ecuador.

Beasley, L., Prawitt, R., \& Rittenberg, G. (2002). COSO Launches New Study on Managing Enterprise. American Accounting Association.

Carrión, H., Mendoza-Vinces, M., \& Álava, C. (2017). Importancia de la auditoría interna para el perfeccionamiento de los niveles eficiencia y calidad en las empresas. Dominio de las Ciencias. 3 (2), 908-920.

Contraloría General del Estado. (2009). Normas de control interno para entidades, organismos del sector público y de las personas jurídicas de derecho privado que dispongan de recursos públicos.

Contraloría General del Estado. (2009). Normas de control interno para las entidades, organismos del sector público y de las personas jurídicas.

Contraloría General del Estado. (2015). Ley Orgánica de la Contraloría General del Estado.

Gaitán, R., \& Niebel, B. (2015). Control interno y fraudes: análisis de informe COSO I, II y III con base en los ciclos transaccionales. Ecoe Ediciones.

García, L. (2016). Indicadores de la gestión logística. Ecoe Ediciones.

Instituto Americano de Contadores Públicos. (1973). Declaración de Normas de Auditoría (SAS No.1). México: Instituto Méxicano de Contadores Públicos (compilación).

Instituto de Auditoría Interna. (2002). Normas para el ejercicio profesional de la auditoría interna.

Internal Control Integrated Framework. (1992).

Ley Orgánica de la Contraloría General del Estado. (2015).

Martínez, M. (2006). La investigación cualitativa (síntesis conceptual). Revista de investigación en psicología. Perú.

Pacheco, C. (2017). Auditoría administrativa a los procesos de contratación pública del Gobierno Autónomo Descentralizado Municipal de San Pedro de Pimampiro por el período comprendido entre enero y diciembre de 2015. Bachelor's thesis, Quito.

Pickett, K. (2007). Manual Básico de Auditoría Interna. Barcelona, España: Gestión 2000.

Potable, E. M. (2004). Manual de Auditoría Interna.

Scrib. (7 de abril de 2016). Obtenido de http://es.scribd.com/doc/306660789/Auditoría-Interna

\section{Licencia Creative Commons CC BY 4.0}

Para citar este artículo: López Jara, A. A., Cañizares Roig, M. y Mayorga Díaz, M. P. (2018). La auditoría interna como herramienta de gestión para el control en los gobiernos autónomos descentralizados de la provincia de Morona Santiago. Cuadernos de Contabilidad, 19(47), 80-93. https://doi.org/10.11144/ Javeriana.cc19-47.aihg 
Anexo 1.

\begin{tabular}{|c|c|c|c|c|c|}
\hline \multicolumn{2}{|c|}{ Entidad } & & & & \\
\hline \multicolumn{2}{|c|}{ Fecha } & & & & \\
\hline \multicolumn{2}{|c|}{ Entrevistado } & & & & \\
\hline N..$^{\circ}$ & Elementos & Sí & No & No aplica & Observaciones \\
\hline \multicolumn{6}{|c|}{ Ambiente de control } \\
\hline \multicolumn{6}{|c|}{$\begin{array}{l}\text { Es el conjunto de circunstancias y conductas que enmarcan el accionar de una entidad desde la perspectiva del } \\
\text { control interno. }\end{array}$} \\
\hline 1 & $\begin{array}{l}\text { ¿Existe un código de ética emitido por la } \\
\text { administración? }\end{array}$ & & & & \\
\hline 2 & $\begin{array}{l}\text { ¿El código de ética es aceptado de forma expresa } \\
\text { por todos los servidores del Instituto? }\end{array}$ & & & & \\
\hline 3 & $\begin{array}{l}\text { ¿El director ha informado sobre las acciones } \\
\text { disciplinarias en el caso de incumplimiento de } \\
\text { las normas de comportamiento? }\end{array}$ & & & & \\
\hline 4 & $\begin{array}{l}\text { ¿Los servidores entienden qué comportamiento } \\
\text { es aceptable o no aceptable? Que si se les } \\
\text { sorprende violando las normas de } \\
\text { comportamiento ¿se les aplicarán las sanciones } \\
\text { previstas? }\end{array}$ & & & & \\
\hline 5 & ¿Se cuenta con un análisis FODA actualizado? & & & & \\
\hline 6 & $\begin{array}{l}\text { ¿Se han dado a conocer a los nuevos servidores } \\
\text { cuáles son sus responsabilidades y lo que la } \\
\text { dirección espera de ellos? }\end{array}$ & & & & \\
\hline 7 & $\begin{array}{l}\text { ¿Se formula un plan de capacitación para el } \\
\text { personal del Instituto? }\end{array}$ & & & & \\
\hline 8 & $\begin{array}{l}\text { ¿La estructura organizativa y funcional permite } \\
\text { cumplir el objetivo del Instituto? }\end{array}$ & & & & \\
\hline 9 & $\begin{array}{l}\text { ¿La asignación de responsabilidad, la } \\
\text { delegación de autoridad y el establecimiento de } \\
\text { politicas conexas, ofrecen una base para el } \\
\text { seguimiento de las actividades? }\end{array}$ & & & & \\
\hline \multicolumn{6}{|c|}{ Evaluación de los riesgos } \\
\hline \multicolumn{6}{|c|}{$\begin{array}{l}\text { El riesgo es la probabilidad de ocurrencia de un evento no deseado que podría perjudicar o afectar adversamente } \\
\text { a la entidad o su entomo. }\end{array}$} \\
\hline 10 & $\begin{array}{l}\text { ¿Los directivos del Instituto identificarán los } \\
\text { riesgos que puedan afectar el logro de los } \\
\text { objetivos institucionales, debido a los factores } \\
\text { internos o externos? }\end{array}$ & & & & \\
\hline 11 & $\begin{array}{l}\text { ¿Se realiza un seguimiento del impacto que } \\
\text { podrian tener estos riesgos sobre los objetivos y } \\
\text { sobre la rentabilidad del Instituto? }\end{array}$ & & & & \\
\hline 12 & $\begin{array}{l}\text { ¿Se conocen los controles que la entidad aplica } \\
\text { en relación con los riesgos identificados? }\end{array}$ & & & & \\
\hline 13 & $\begin{array}{l}\text { ¿Existen mecanismos adecuados para identificar } \\
\text { riesgos de fuente interna? ¿Se consideran } \\
\text { criterios como, recursos humanos, presupuesto, } \\
\text { sistemas de información y diseño de los } \\
\text { procesos, entre otros? }\end{array}$ & & & & \\
\hline
\end{tabular}




\begin{tabular}{|c|c|c|c|c|c|}
\hline \multicolumn{2}{|c|}{ Entidad } & & & & \\
\hline \multicolumn{2}{|c|}{ Fecha } & & & & \\
\hline \multicolumn{2}{|c|}{ Entrevistado } & & & & \\
\hline N. ${ }^{\circ}$ & Elementos & Sí & No & No aplica & Observaciones \\
\hline \multicolumn{6}{|c|}{ Actividades de control } \\
\hline \multicolumn{6}{|c|}{$\begin{array}{l}\text { La máxima autoridad de la entidad y las servidoras y servidores responsables del control intemo, de acuerdo con } \\
\text { sus competencias, establecerán politicas y procedimientos para manejar los riesgos en la consecución de los } \\
\text { objetivos institucionales, proteger y conservar los activos y establecer los controles de acceso a los sistemas de } \\
\text { información. }\end{array}$} \\
\hline 14 & $\begin{array}{l}\text { ¿Se elaboró el plan anual de actividades del } \\
\text { Instituto en coordinación con los servidores de } \\
\text { las diferentes áreas? }\end{array}$ & & & & \\
\hline 15 & $\begin{array}{l}\text { ¿Se ha procurado la rotación de tareas, de } \\
\text { manera que exista independencia, separación de } \\
\text { funciones incompatibles? }\end{array}$ & & & & \\
\hline 16 & $\begin{array}{l}\text { ¿Existen manuales, instrucciones o normas } \\
\text { escritas acerca de cómo se deben desarrollar las } \\
\text { diversas actividades de trabajo? }\end{array}$ & & & & \\
\hline 17 & $\begin{array}{l}\text { ¿Los responsables de cada departamento } \\
\text { diseñan controles relacionados con los planes y } \\
\text { programas de la actividad que desarrollan? } \\
\text { Asimismo, ise diseñan politicas y controles para } \\
\text { velar porque las actividades cumplan sus } \\
\text { objetivos especificos? }\end{array}$ & & & & \\
\hline 18 & $\begin{array}{l}\text { ¿Se han implementado medidas de control } \\
\text { interno con la finalidad de combatir el fraude y } \\
\text { la cornupción? }\end{array}$ & & & & \\
\hline \multicolumn{6}{|c|}{ Información y comunicación } \\
\hline \multicolumn{6}{|c|}{$\begin{array}{l}\text { La máxima autoridad y los directivos de la entidad deben identificar, capturar y comunicar infamación pertinente } \\
\text { y con la oportunidad que facilite a las servidoras y servidores cumplir sus responsabilidades. }\end{array}$} \\
\hline 19 & $\begin{array}{l}\text { ¿Se identifica y presenta con regularidad la } \\
\text { información, generada dentro de la } \\
\text { organización, crucial para el logro de los } \\
\text { objetivos de la entidad? }\end{array}$ & & & & \\
\hline 20 & $\begin{array}{l}\text { ¿La información se facilita con el detalle } \\
\text { adecuado para los distintos niveles de gestión? }\end{array}$ & & & & \\
\hline 21 & $\begin{array}{l}\text { ¿La calidad y oportunidad de la información } \\
\text { permite la toma de decisiones adecuada, tanto } \\
\text { hacia la máxima autoridad como a los jefes } \\
\text { departamentales? }\end{array}$ & & & & \\
\hline 22 & $\begin{array}{l}\text { ¿Existe la suficiente comunicación que facilite } \\
\text { al personal del Instituto a cumplir sus } \\
\text { funciones? }\end{array}$ & & & & \\
\hline 23 & $\begin{array}{l}\text { ¿La información se transmite a los niveles } \\
\text { superiores de la organización según sea } \\
\text { necesarioy se realizan acciones de seguimiento? }\end{array}$ & & & & \\
\hline \multicolumn{6}{|c|}{ Monitoreo } \\
\hline \multicolumn{6}{|c|}{$\begin{array}{l}\text { La máxima autoridad y los directivos de la entidad establecerán procedimientos de seguimiento continuo, } \\
\text { evaluaciones periódicas o una combinación de ambas para asegurar la eficacia del sistema de control interno. }\end{array}$} \\
\hline 24 & $\begin{array}{l}\text { ¿El director del Instituto realiza un seguimiento } \\
\text { continuo de las actividades que cada una de las } \\
\text { unidades realiza, que permita aplicar medidas } \\
\text { oportunas? }\end{array}$ & & & & \\
\hline 25 & $\begin{array}{l}\text { ¿Existen procedimientos para que la dirección } \\
\text { revise los procesos de control para asegurarse de } \\
\text { que se aplican los controles de la forma } \\
\text { esperada? }\end{array}$ & & & & \\
\hline 26 & $\begin{array}{l}\text { ¿Se investigan las quejas presentadas por los } \\
\text { proveedores? }\end{array}$ & & & & \\
\hline 27 & $\begin{array}{l}\text { ¿Toma la dirección acciones adecuadas y } \\
\text { oportunas para corregir deficiencias reportadas } \\
\text { por la función de la auditoria interna? }\end{array}$ & & & & \\
\hline \multicolumn{2}{|r|}{ Subtotal } & & & & \\
\hline Por & entaje de cumplimiento \% & & & & \\
\hline
\end{tabular}

